\title{
Study on the Inspection Testing \& Certification by Game Theory
}

\author{
Zhaoying Zuo ${ }^{1,2}$, Deshan Tang ${ }^{1}$, Shangrui $\mathrm{Wu}^{2}$, Xiaodan Yang ${ }^{2}$, Jian 'Sun \\ 2 Yixian Wang ${ }^{2}$, \\ ${ }^{1}$ Business Department Hohai University, Nanjing , Jiangsu Province, China \\ ${ }^{2}$ Rizhao Inspection and certification company, Rizhao, Shandong Province, China \\ E-mail: zuozhaoying0531@sina.com
}

Keywords: Inspection testing and certification, Finite repeated game, Multiple governance

\begin{abstract}
Firstly, we analysis the common character of inspection testing and certification. Then based on the theory of game theory ,the paper analysis the act of finite repeated game by the coal ore inspection. Some measures should be taken to enhance the international competitiveness of the inspection testing and certification industry.
\end{abstract}

\section{Introduction}

Inspection testing\& certification industry are the national quality foundation and they have been regarded by the State Council as one of the eight high technology service industries and eleven largest producer services. It originates from information asymmetry, aiming to provide information to make the trade activities stability, which essentially to offset market defects and supplement market system under the supervision of society and government.

The scale of inspection testing and certification market in China had been more than 100 billion yuan in 2013 and become to the third largest market(see Table 1),rank only second to the United States and the the European Union area,which is expected to exceed 250 billion yuan by the year 2020.Recently, certification industry in China increasing about $10 \%$ every year. In 2014,the valid certificates issued by the certification authority has been more than 1.3 million copies, increased by $11.6 \%$ compared to 2013,in which more than 60 million management system certificate and nearly 1500 copies of Service certificates. The scale of the market increased steadily in 2014, totally issued 311 million report to the society, which rose $9.89 \%$ compared with 2013.In 2014 our country established more than 2.8 testing institutions, the revenue has reached 160 billion yuan. The amount of national certification institution is 218 , and annual revenue is 22 billion yuan.

Table 1 . The Scale of quality inspection\&testing industry from 2011-2015 (From AQSIQ )

\begin{tabular}{|l|l|l|l|l|l|}
\hline Years & 2011 & 2012 & 2013 & 2014 & 2015 \\
\hline Scale & 82.7 & 108.4 & 139.9 & 175.4 & 214.5 \\
(Billion) & & & & & \\
\hline
\end{tabular}

The main research focus on certification body and some paper research the service quality of certification body[1][2][3] ,Collusion-proof of certification[4][5][6], the legal attribute and the basic characteristics of certification[7].But the research on inspection and testing is less scattered in[8][9].Actually, the inspection and testing has the similar character of certification such as independence and impartiality and both are an activity facilitate smooth transaction and a necessary lubricate for effective economic operation[10].Also both improving market system through their marketization under social and governmental regulation. The research on inspection testing and certification is also less, such as scattered in [10] and [11].The paper try to fill the gap. 


\section{Economic Analysis}

Take coal inspection and testing as an example, The main relevant parties include regulator, buyer, seller and inspection and testing body. The buyer and the seller sign up the contract that appointed one certain inspection and testing body to take sample, prepare sample and analysis the

sample, then issue the certificate including analysis of the result such as the Ash, Sulfur, Moisture as the settlement .In the coal inspection and testing process, the applicant(buyer or seller) and the regulator maybe one shot game, but the inspection and testing body and the regulator are finite repeated games. The importance of repeated frequency depend on the short-time benefits and benefits in the long-run, we should consider the effect of reputation in the process.

Suppose the regulator at the stage of $n=0$ believe the prior probability of inspection and testing body high reputation was $\mathrm{p}$, the prior probability of inspection and testing body low reputation was 1-p. In the repeated game stage $T$, suppose $b_{t}$ is the probability of cooperation at he stage of $t$ of high reputation inspection and testing body . $a_{t}$ is the probability of cooperation at he stage of $t$ of low reputation inspection and testing body .Under the condition of equilibrium, $a_{t}$ $=b_{\text {t. }}$. If at the stage of $t$, the regulator discover inspection and testing body use the tactics of cooperation, that is $r_{t}=1$. According to Bayes' theorem, the regulator believe the posterior probability of high reputation of the inspection and testing body is

$$
\mathrm{p}_{\mathrm{t}+1}\left(\mathrm{G}_{1} \quad \mathrm{r}_{\mathrm{t}}=1\right)=\quad \frac{\mathrm{p}_{\mathrm{t}} \times 1}{\mathrm{p}_{\mathrm{t}} \times 1+\left(1-\mathrm{p}_{\mathrm{t}}\right)\left[\mathrm{a}_{\mathrm{t}}+\left(1-\mathrm{a}_{\mathrm{t}}\right)\left(1-\mathrm{p}_{\mathrm{t}}^{\prime}\right)\right]}
$$

The $p^{\prime} t=(1-p n)(1-a n)$ is the probability of regulator supervise. If at $<1$, the (1) is correct. If the is ' no cooperation' was detected by the regulator,that is $\mathrm{rt}=0$

$$
\mathrm{p}_{\mathrm{t}+1}\left(\mathrm{G}_{1} \mid \mathrm{r}_{1}=0\right)=\frac{\mathrm{p}_{\mathrm{t}} \times 0}{\mathrm{p}_{\mathrm{t}} \times 0+\left(1-\mathrm{p}_{\mathrm{t}}\right)\left[\mathrm{a}_{\mathrm{t}}+\left(1-\mathrm{a}_{\mathrm{t}}\right)\left(1-\mathrm{p}_{\mathrm{t}}^{\prime}\right)\right]}=0
$$

If the inspection and testing body was no cooperation, the regulator believe probability of the body use the tactics of cooperation is 0 and the body was excluded from the inspection\&testing market.

If the inspection and testing body was keeping high reputation before the stage of $n-1$, we can conclude that pn-1>0.The regulator conclude the body use the tactics of no cooperation is p'n-1=(1-pn-1)(1-an-1), and the probability of supervise is p'n-1,the force of supervision is monotone decrease function of the the reputation of the inspection and testing body .

If the inspection and testing body use the tactics of no cooperation at the stage of $n-1$, the total utility of inspection and testing body was

$\pi_{1}=\mathrm{U}_{\mathrm{n}-1}^{\mathrm{T}}+\delta \mathrm{U}_{\mathrm{n}-1}^{\mathrm{T}}=\mathrm{g}\left(\mathrm{E}_{\mathrm{r}}\right)+\left[\left(1-\mathrm{p}_{\mathrm{n}-1}^{\prime}\right) \cdot \mathrm{b}_{2} \mathrm{~h}-\mathrm{p}_{\mathrm{n}-1}^{\prime} \mathrm{s}\right]+\delta\left(1-\mathrm{p}_{\mathrm{n}-1}^{\prime}\right) \cdot\left\{\mathrm{g}\left(\mathrm{E}_{\mathrm{r}}\right)+\left[\left(1-\mathrm{p}_{\mathrm{n}}^{\prime}\right) \cdot \mathrm{b}_{2} \mathrm{~h}-\mathrm{p}_{\mathrm{n}}^{\prime} \mathrm{s}\right]\right\}$

(3)

Er is the actual testing result by inspection and testing body,$\delta$ is discount factor,r is benchmark

Interest rate. $\delta=1 /(1+\mathrm{r}), \mathrm{s}$ is penalty.

If the inspection and testing body use the tactics of cooperation at the stage of $n-1$, the total utility of inspection and testing body was

$\pi_{2}=\mathrm{UTn}-1+\delta \mathrm{UTn}-1=\mathrm{g}(\mathrm{Er})+\delta \cdot\left\{\mathrm{g}(\mathrm{Er})+\left[\left(1-\mathrm{p}^{\prime} \mathrm{n}\right) \cdot \mathrm{b} 2 \mathrm{~h}-\mathrm{pn} \mathbf{s}^{\prime}\right]\right\}$ 
If the body willing to cooperation, $\mathrm{S}_{2}$ should be no less than $\pi_{1} \delta p_{n-1}^{\prime} \cdot\left\{g\left(E_{r}\right)+\left[\left(1-p_{n}^{\prime}\right) \cdot b_{2} h-p_{n}^{\prime} s\right]\right\} \geq\left[\left(1-p_{n-1}^{\prime}\right) \cdot b_{2} h-p_{n-1}^{\prime} s\right]$

(5)

From the stage of $\mathrm{n}$ during repeated game, The regulator can establish the reputation mechanism to make the inspection and testing body cooperation.At the final stage, the body maybe apt to get the maximum benefit before exiting the market. We can analysis the certification and other inspection testing by the similar way.

\section{The strategy option on developing the industry}

Firstly, it is urgent to promote independent industry regulatory system and draw lessons from independent regulatory system of American accountants industry in order to overcome lack transparent supervision to the industry and association and low efficiency of the government regulation; strengthen the legal status of inspection testing and certification.

Secondly, it is necessary to learn from international experience of giving more play to the inspection testing and certification bodies and associations and eliminate the industry division. Governments need to entrust and purchase quality services.

Thirdly, measures should be taken to improve supervision mechanism in or after the event and collect data together, then analysis relevant of data while improving the ability of the government on decision-making. If certain quality problems happened,the supervision department could coordinate and take fund for compensation to strengthen the supervision of institutions in order to form lifelong credit tracking system.

Fourthly, it is essential that set up funds and other ways to mobilize the mass enthusiasm on reporting violations of inspection testing and certification orders meanwhile keep strictly secret for informers[12].Relevant department should perfect complaint handling systems and procedures in order to timely handling complaints accordingly.

\section{Conclusion}

Through analysis of the common characters of inspection testing and certification, based on the theory of game theory ,the paper analysis the act of finite repeated game by the coal ore inspection and provided four strategy options: 1). promote independent industry regulatory system and draw lessons from independent regulatory system of American accountants industry; 2) give more play to the inspection testing and certification bodies and associations and eliminate the industry division; 3) improve supervision mechanism in or after the event, do data analysis to improve the ability of the government on decision-making; 4) set up funds and other ways to mobilize the mass enthusiasm on reporting violations of inspection testing and certification orders meanwhile keep strictly secret for informers.

\section{Reference}

[1]Castka, Pavel \& Prajogo, Daniel \& Sohal, Amrik \& Yeung, Andy (L., Understanding firms' selection of their ISO 9000 attyirceptifiers, International Journal of Production Economics,2015.162(C), 125-133

[2]Su Qin, Cui Yan Wu, Dang Ji Xiang A Study on Measuring Service Quality in B2B Context Based on Certification Service Industry[J] MANAGEMENT REVIEW Vol.22 2010(7)

[3]Su xian, Su Qin, Song Yongtao, Cui Yanwu The service quality of certification agencies on relationship quality[J] Science Research Management, 2011 (3) 
[4]Strausz R. Honest Certification and the Threat of Capture[J]. Discussion Paper, 2004, 23(s 1-2):45-62.

[5]Huang Xin ,Tao Xiaoma ,Xing Jianwu, Analysis on Collusion-proof for Authentication Mechanism of Tradable Energy Saving Certificates[J] Economic Management Journal 2009(11)

[6]Chen Yanying, Bao Zongke, Optimal Number Structure of Certification Industry in China under Exogenous Collective Reputation Constraints Journal of Finance and Economics 2014(8)

[7]Legal Attribute and the Basic Characteristics of theThird Party Certification Authority-Based on the analysis of social intermediary body theory[J] Hebei Law Science 2015(11)

[8]Wang Lafang Li Ximeng, Hejiang Much starker choices-and graver consequences-in period inspection testing service industry development strategy research in China $[\mathrm{J}] \quad$ Economic Review 2015(5).

[9]Zhang Rongmei Supervision for the import and export commodity inspection appraisal organization work[J] China inspection and quarantine 2012(2)

[10]Jin Bei, Wang Yan-mei, Chen Xiao-dong The Nature of Economics of Inspection and Certification and Its Industrial Regulation -Based on the Survey over China's Inspection and Certification Bodies[J] Economic Management Journal in China 2012 (1)

[11]Liu R, Cui L, Zeng G, et al. Applying the fuzzy SERVQUAL method to measure the service quality in certification \& inspection industry[J]. Applied Soft Computing, 2015(26): 508-512.

[12]Liu Changyu, Yu Tao Study on the tripartite game in quality regulation of green products China Population, Resources and Environment 2015(10) 